\title{
Development of the Inventory Management System for ERP Implementation in Manufacturing Industry
}

\author{
Sushil Kumar Choudhary ${ }^{1}$, Niraj Gupta ${ }^{2}$ \\ ${ }^{I}$ Department of Production Engineering, G.B.Pant University of Agriculture \& Technology \\ Pantnagar,U.S.Nagar, Uttarakhand, India \\ ${ }^{2}$ Faculty of Mechanical Engineering, Shri Ramsawroop Memorial University, \\ Lucknow-Deva Road, Barabanki, U.P., India
}

\begin{abstract}
This paper deals with development of inventory management system for a manufacturing Industry. The developed software System is easy to use, less time consuming \& all detail about the inventory items \& transaction status. Enterprise Resource Planning (ERP) software presents a frame work for organizations to better utilize their processes. The report is about windows based application. The Front-end is developed using Visual Basic. A visual programming environment provides all features that are required to develop graphical user interface as ready to use components. The programmer does not have to write code to create and display commonly required user-friendly features each time around. The Backend used is SQL server database that ensures total security and no data loss or corruption. The database management systems are warehouses of information, where large amount of data can be stored. The Reports are developed using Crystal Report. Crystal Reports is the standard reporting tool for Visual Studio .NET. It brings the ability to create interactive, presentation-quality content; to the .NET platform. Crystal report is an integral part of the Visual Studio .NET environment. The main idea of this paper is to handle the all details of inventory management system. In this software package has been developed to smoothen the processing of item transaction in inventory such as item receive, item issue \& report generation such as stock statement, issue register \& receive register etc. This Software will help in automating all the process like receiving and issuing application in inventory.
\end{abstract}

Key Words: ERP, Inventory management, Front-end Database SQL, Back end-Visual basic

\section{Introduction}

ERP is the acronym of Enterprise resource planning. ERP basically utilizes ERP software applications to improve the performance, efficiency, facility, data security, eliminate human error, reduction data entry and speedy accurate reporting of material transaction of organization. Enterprise Resource Planning (ERP) is the last state of a system that has been released in 1960's, which have been called Material Requirements Planning (MRP). The main aim of MRP systems was calculating the material requirements according to time stamps with the help of computerized systems. MRP was developed to calculate more efficiently the materials needed. The improvements in the computer systems and operational needs that require cooperation and co-ordination of various departments (quality control, finance, sales, production planning etc.) in a firm have moved the MRP system one step further; Manufacturing Resource Planning (MRPII). MRPII was enough for firms until 1990's, the decade that globalize started to be effective on business processes. Firms became to sell and buy goods, services from everywhere in the world without considering the limits of distance. At that point, the MRPII functions had to be modified and re-designed for a firm that has different locations and branches around the world. Therefore, "Enterprise" concept has come to the scene. The planning function has to be deployed at the enterprise level. New software application then called Enterprise Resource Planning (ERP).Early generation of ERP systems entirely focused on infrastructure renewal and creating efficiencies in back office operations around key functional areas such as finance and production management. These systems, while useful, did not address the mission critical issues such as supply chain management (SCM), customer relationship management (CRM), and knowledge management (KM). New generation systems have sought to address these shortcomings in a variety of ways. Also, while early generation ERP systems were found mainly in large organizations, newer systems are now being targeted at small and medium enterprises as means of expanding the ERP market, 
Table-1 ERP Evaluation

\begin{tabular}{|l|}
\hline ERP Evaluation \\
\hline \hline In 1960s, Inventory Management \& Control \\
\hline In 1970s, Material Requirement Planning (MRP) \\
\hline In 1980s, Manufacturing Requirements Planning (MRP II) \\
\hline In 1990s, Enterprise Resource Planning (ERP) \\
\hline In 2000s, Extended ERP \\
\hline
\end{tabular}

\section{Case Study: About The Organization}

The ABC Company is the only flashlight plant of the parent company. This is the light engineering industry. Most of the metal sheet work is being done along with some plastic components molding. The Plant manufactures the full Range of DigiLed, Brass, aluminum and plastic torches.

Inventory mainly classified into three categories:

1. Raw material items inventories

2. Engineering equipment Inventories

3. Packaging material

4. Finish product Inventories

Main objective of the present work is to develop software package for inventory management system. Inventory transaction mainly classified into three modules 1 . Items received in side 2 . Items issue in-side 3. Items issue (outside). Inventory report generation are stock statement, issue resister, receive resister.

\section{Software Development Lifecycle}

A framework that describes the activity performed at each state of software development project is given in Fig.1. In this project waterfall model is used. Water fall strengths mainly are: Easy to understand easy to used, Provide structure in experience staff, milestone are well understood, Sets requirement stability, Good for management control, Requirements are very well known, product definition is very well.

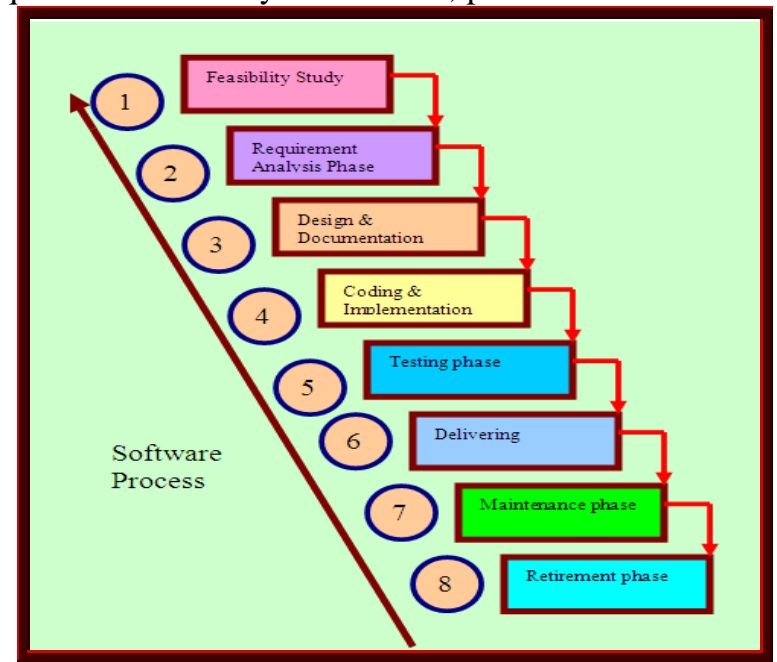

Fig.1: Software development life cycle (water fall model)

3.1 Feasibility study: In this step we study about the feasibility of the inventory management system. At present the Inventory management of The ABC Company does not have any automated system to manage the data of receiving, issuing of raw material, capital goods, packing material and finish product. They have to rely on manual system which is time consuming. They have to create and maintain all the data masters for addition, deletion or modification to any data or retrieval of data that requires lot of time and effort.

Limitations of the Manual System:

- Maintenance and updating data is difficult.

- It is very tedious.

- All information is not placed separately.

- Slow Speed and very time consuming.

- Not user-friendly environment.

- Storage of bulky files is a problem.

- It is difficult to found records 
- $\quad$ No efficient method for searching the record of the particular state.

We proposed a new system in which all the details of material, product transaction handled by a computerized system rather than a manual system. The following performance characteristics should be taken care of while developing the system:

- User friendliness

- User satisfaction.

- Response time

- Error handling

- Robustness

- Faster response

- Complete Security of Data

3.2 Requirement analysis phase: In this phase, we study about the software requirement specification \& analysis. Requirement Analysis is the process of understanding the customer \& users and expectations from a proposed system or application and is well defined stage in the software development. Basic requirement such as user \& top management, software, hardware, Technology, Inventory management module, report, master data, etc

\subsubsection{User \& Top management Requirements}

Top management and current users' basic requirement of integrated store management are:

A. Result required for items issue Transactions

- Material document is created-When you transaction an items issue, the system automatically creates a material document which serves as proof of the items issue transaction.

- Accounting document is created-Parallel to the material document; the system creates an accounting document.

- Items issue slip is created-When you enter the items issue, you can print the items issue slip at the same time

- Stock update-After the issue or receive transaction stoke should be updated.

- Consumption update- any types of items consumption should be updated

B. Result required of items Receipt Transactions

- Creation of a Material Document-When you post a items receipt, the system automatically creates a material document which serves as proof of the items movement.

- Creation of an Accounting Document-Parallel to the material document, the system creates an accounting document.

- Creation of an Item Receipt-When you enter the items receipt, you can print the items receipt at the same time.

- Stock Update-Which stocks are updated in the material master record depends on the destination of the items. The stock value is updated at the same time.

\subsubsection{Technology requirement for ERP Software development}

A. Client/Server technology- The Client/Server technology model is the model on which today's software's is developed. A Client/ Server model is one in which the client computer is identified separately from the server computer. Typically, in a client/server environment, the desktop computers are connected using networking devices like hubs and routers to centrally located servers like database servers, application servers, print servers and file servers.

B. The Front-end is developed using Visual Basic. A visual programming environment provides all features that are required to develop graphical user interface as ready to use components. The programmer does not have to write code to create and display commonly required user-friendly features each time around.

C. The Backend used is SQL server database that ensures total security and no data loss or corruption. The database management systems are warehouses of information, where large amount of data can be stored.

\subsubsection{System Requirements}

System requirement are two Types- Software \& Hardware

1. Software Requirement

- $\quad$ Visual Studio .Net 2005

- SQL Server 2005

- Operating system: - Windows XP 
- $\quad$ Front End: - Visual Basic 6.0.

- Database- SQL

- Back end: - SQL Database

\section{Hardware Requirement}

- Processor: - Intel Pentium III 833MHz

- RAM: - 256MB

- Hard Disk: -80 GB

- Monitor: - 14"VGA.

- Mouse. Any one

- Printer: - For print report or Bill.

3.2.4 Requirement for inventory management modules \& report of the inventory

A. Material Transaction Entry

Material Transaction in inventory management classified is three types;

1. Item or product Received Entry

- MRN No. - It determine the voucher no of the received item or product

- MRN Date- Its determine the receipt date of the item or product

- Invoice no.-It specifies the Invoice number.

- Invoice Date-It specifies the invoice date.

- Vendor Name- The complete name of the Vendor.

- Vendor code- It specifies the Vendor code.

- Vendor address-It determines the address of the Vendor.

- Item Name-It contains the name of the item.

- Item code-It represents the code to identify an item. It helps to search the item in the stock according to requirement.

- Qty. - It specifies the received quantity.

- $\quad$ Price-It specifies the per unit price.

- Amount- It specifies the amount of item or product.

- Total Amount-It specifies the total amount of Receiving

\section{Issue Item or product Entry In house}

- Issue No.- It determine the issue number of the item or product

- Issue Date- Its determine the Issue date of the item or product

- Issuing party- Employee \& subcontractor

- Issuing party member id-Employee \& subcontractor code.

- Issuing party member name-The complete name of the Employee \& Subcontractor.

- Item or product Name-It contains the name of the item or product.

- Item code-It represents the code to identify an item.

- Qty.-It specifies the Issue quantity.

- $\quad$ Price-It specifies the per unit price.

- Amount-It specifies the amount of item or product.

- Total Amount-It specifies the total amount of issue item or product

\section{Issue Item or product Entry Outside}

- Issue No.-It determine the issue number of the item or product

- Issue Date-Its determine the Issue date of the item or product

- Issuing party-Vendor, customer, supplier, maintenance vendor

- Issuing party member id-Vendor, customer, supplier, \& maintenance vendor code.

- Issuing party member name-The complete name of the vendor, customer ,supplier, \& maintenance vendor

- Item or product Name- It contains the name of the item or product.

- Type of item- Specifies the type of item.

- Item code-It represents the code to identify an item.

- Qty.-It specifies the Issue quantity.

- $\quad$ Price-It specifies the per unit price.

- Amount-It specifies the amount of item or product. 
- Total Amount-It specifies the total amount of issue item or product

\author{
B. Report of the Inventory \\ 1. Stock statement \\ 2. Issue Register \\ 3. Receive Register \\ 4.
}

\title{
3.3 Designing \& documentation
}

In this phase,we study about the software design \& description. Designing is the most important phase of software development. It requires a careful planning and thinking on the part of the system designer. Designing software means to plan how the various parts of the software are going to achieve the desired goal. In this stage development of DFD, ER Diagram, \& design of database etc.

A. Data flow diagram: Data Flow Diagramming is a means of representing a system at any level of detail with a graphic network of symbols showing data flows, data stores, data processes, and data sources/destinations. The goal of data flow diagramming is to have a commonly understood model of a system.

B. Entity Relationship Diagram-An ER diagram is a graphical representation of an organization's data storage requirements. The entity- relationship (E-R) model is a high-level data model. It is based on a perception of real world that consist of collection of basic objects, called entities, and of relationships among these objects, It was developed to facilitate database design by allowing specification of an enterprise schema, which represent the overall logical structure of database.

C. Design of database-Database design is the process of producing a detailed data model of a database. The term database design can be used to describe many different parts of the design of an overall database system. Database management systems (DBMSs) are computer software applications that interact with the user, other applications, and the database itself to capture and analyze data. A general-purpose DBMS is designed to allow the definition, creation, querying, update, and administration of databases.

\subsection{Coding \& implementation}

Using coding techniques and good programming practices to create high quality code plays an important role in software quality and performance. The system design needs to be implemented to make it a workable system. This demands the coding of design into computer understandable language, i.e., programming language. This is also called the programming phase in which the programmer converts the program specifications into computer instructions, which we refer to as programs. It is an important stage where the defined procedures are transformed into control specifications by the help of a computer language. During this phase, all the programs of the system are loaded onto the user's computer. After loading the system, training of the user starts. Main topics of such type of training are:

- How to execute the package

- How to enter the data

- How to process the data (processing details)

- How to take out the reports

\subsection{Testing phase}

During the testing phase representatives from all user groups need to be involved for functionality and usability testing. The aim of testing process is to identify all defects in a software product. Testing is any activity aimed at evaluating the software for quality results it produces and the quality of results it can handle. Testing is an operation to detect the differences between the expected (required) result and the actual result.

\subsection{Delivery phase}

Most of the Software Development methodologies seem to stop once development has finished. Yet the acceptance testing and deployment process are fundamental to the success of the project as a whole. What's more, there are very few organizations who have the necessary expertise in house to make either of these processes a success. 


\subsection{Maintenance phase}

In this phase is necessary to eliminate errors in the system during its working life and to tune the system to any variations in its working environments. It has been seen that there are always some errors found in the systems that must be noted and corrected. It also means the review of the system from time to time.

\subsection{Retirement phase}

In this phase last steps of software development life cycle. The goal of this phase is the removal of a system release from process work, and occasionally even the complete system itself, an activity also known as system decommissioning or system sun setting. Retirement of systems is a serious issue faced by many organizations today as legacy systems are removed and replaced by new systems. You must strive to complete this effort with minimal impact to business operations.

\section{Results}

Result provide the easy, fast and accurate system for issuing, receiving \& and Report generation of the item transaction in the inventory management system. Main user interface of inventory management are:

A. User authentication: The use of a password and username is the most common form of authentication used and is generally considered the cheapest and most convenient method. User authentication is a means of identifying the user and verifying that the user is allowed to access some restricted service. The server administrator needs to be able to control access on an individual basis; it is possible to require a username and password before being allowed access to a document. This is called user authentication. This is the login screen. Here the user (i.e. the authorized official) will login by using their right user id \& Password.

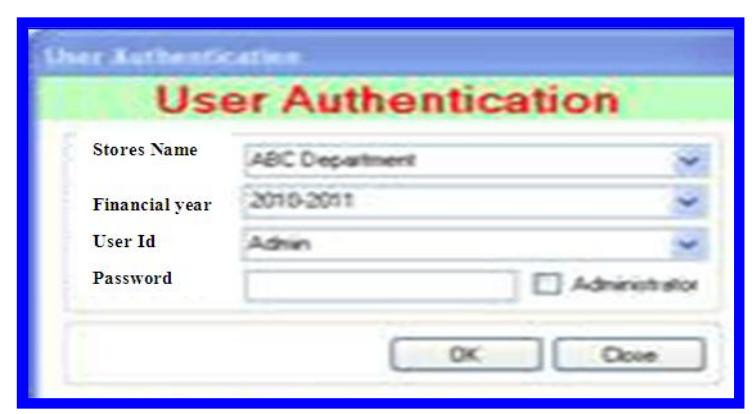

Fig.2: user authentication

\section{(B) Menu interface of inventory management}

1. Administrator

2. Master data

3. Transactions

4. Report

5. Exit

1. Administrator: A data base administrator (DBA) directs or performs all activities related to maintaining a successful database environment. Responsibilities include designing, implementing, and maintaining the database system; establishing policies and procedures pertaining to the management, security, maintenance, and use of the database management system; and training employees in database management and use. The following is the interface to insert record of user management.

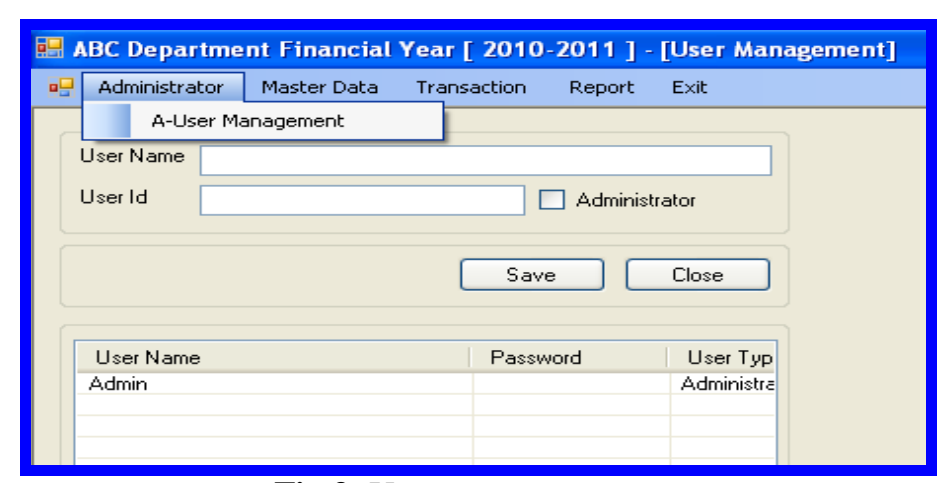

Fig.3: User management 
2. Master Data: Most software systems have lists of data that are shared and used by several of the applications that make up the system. Master data may include all the data about customers, maintenance vendor, vendor, employees, suppliers, Sub contractor \& items. Master data is typically shared by multiple users and groups across an organization and stored on different systems. Insert record of master data. The information about the master data member \& items showing in the fig. $5 \&$ fig. 6

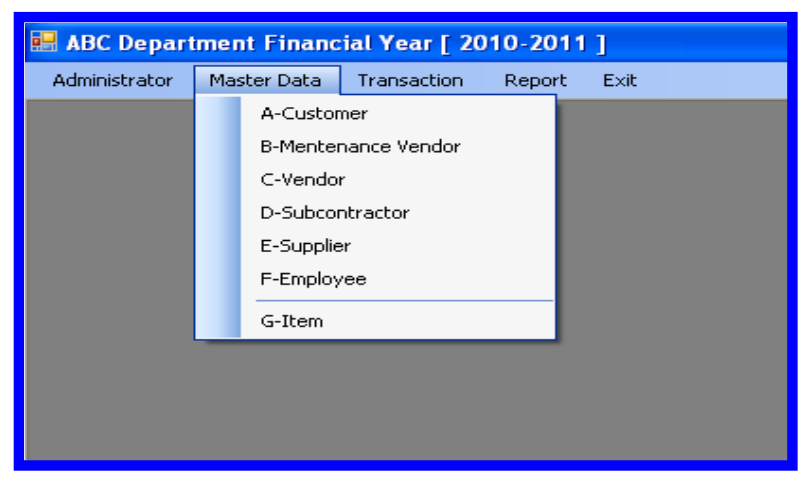

Fig.4: Type of Master Data

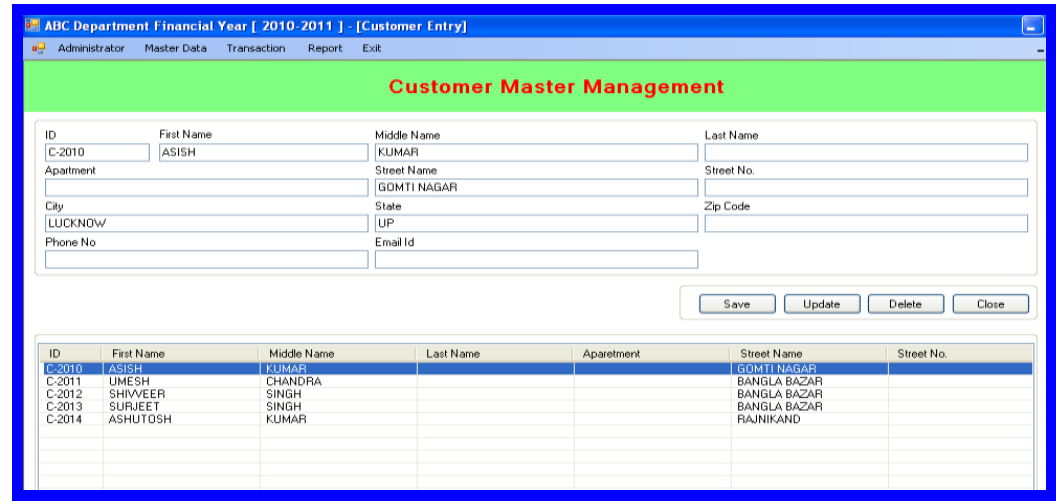

Fig.5 Customer Master Management

1. Customer Entry: Maintain the customer list, every customer Details \& it can be save, update, delete \& close the entry.

2. Maintenance Vender Entry: Maintain the maintenance vendor list, every maintenance vendor Details \& it can be saved, update, deletes \& closes the entry.

3. Vendor Entry: Maintain the maintenance vendor list, every maintenance vendor Details \& it can be saved, update, deletes \& closes the entry.

4. Subcontractor Entry: Maintain the subcontractor list, every subcontractor Details \& it can be saved, update, deletes \& closes the entry.

5. Supplier Entry: Maintain the supplier list, every supplier Details \& it can be saved, update, deletes \& closes the entry.

6. Employee Entry: Maintain the Employee list, every employee Details \& it can be saved, update, deletes \& closes the entry.

7. Item or product Entry: Maintain the product or item list, every item details \& it can be saved, update, deletes \& closes the entry. 


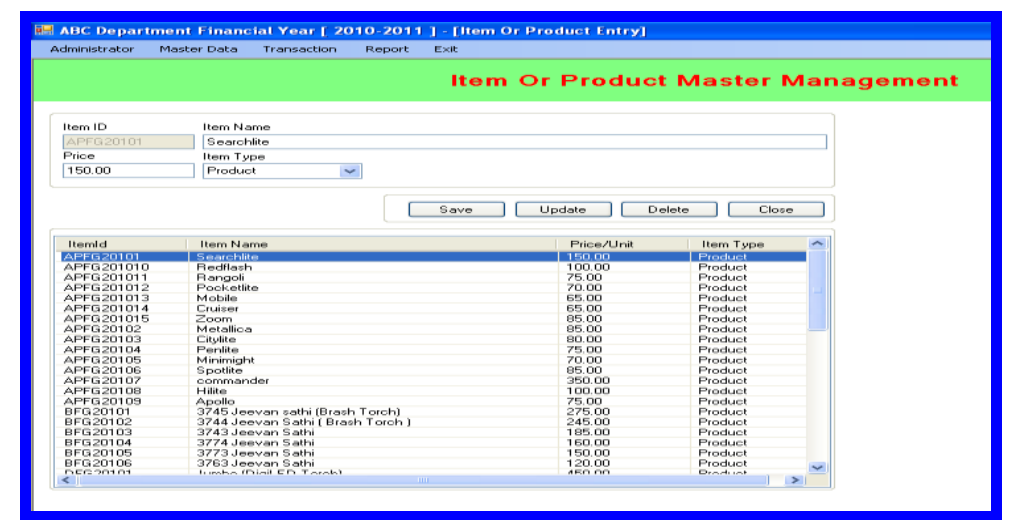

Fig.6: Item or product Master management

3. Transactions: A transaction is an agreement, communication, or movement carried out between separate entities or objects, often involving the exchange of items of value, such as information, goods, services, and money. Transaction in the stores management classified is three types;
A- Receive material
B- Issue Item in House
C- Issue item in outside

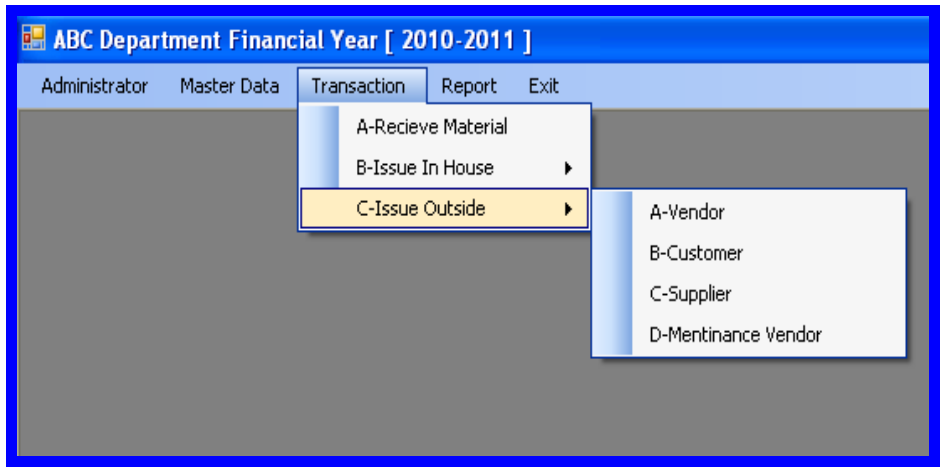

Fig.7: Transaction Type

A-Items or product receive entry: In this Entry receive of item party wise, date wise \& it can be new MRN, save, update, delete $\&$ close the entry.

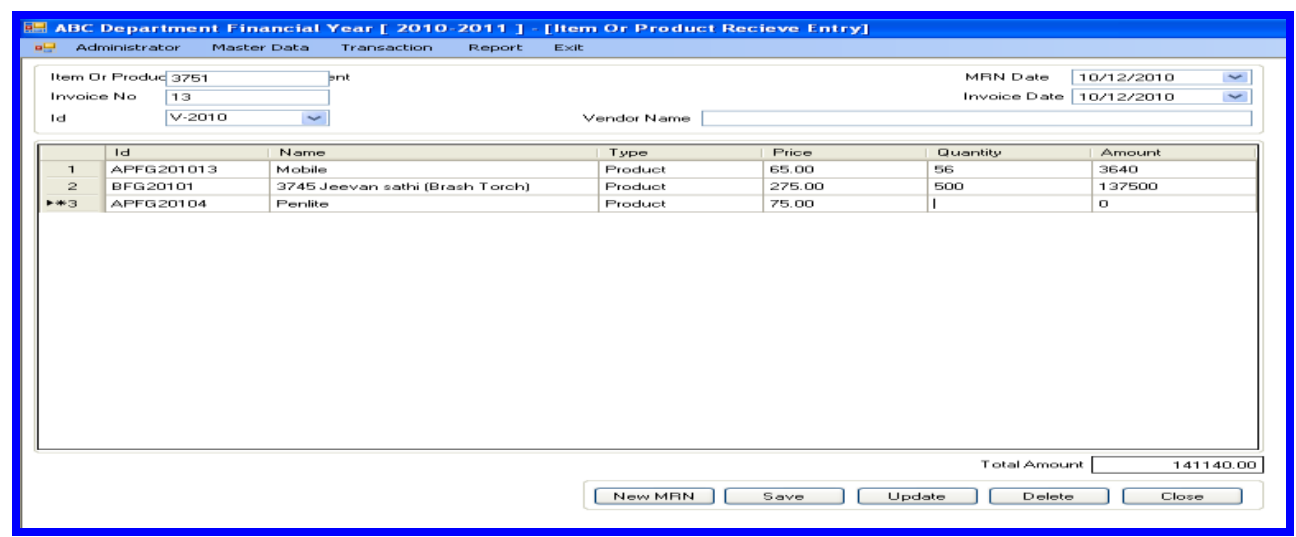

Fig.8 Item Receive Entry

B. Issue items in- house party entry: In this entry issue of item in house according to the party and date wise such as: Employee. Sub contractor. \& it can be new issue, save, update, delete, and print \& close the entry. 


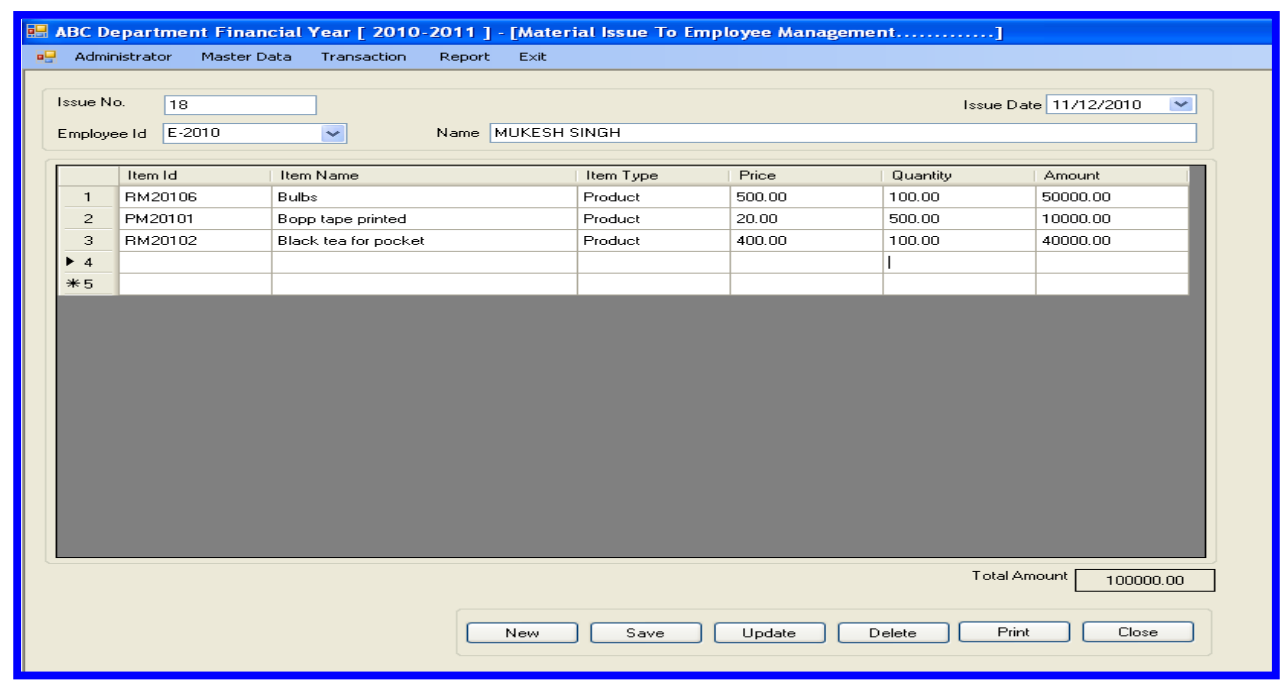

Fig.9 Issue item in -house party entry

C- ISSUE ITEM TO OUTSIDE PARTY ENTRY: In this entry issue of item in outside according to the party $\&$ date wise such as: Supplier, vendor, customer, maintenance vendor, \& it can be new issue, save, update, delete, and print \& close the entry.

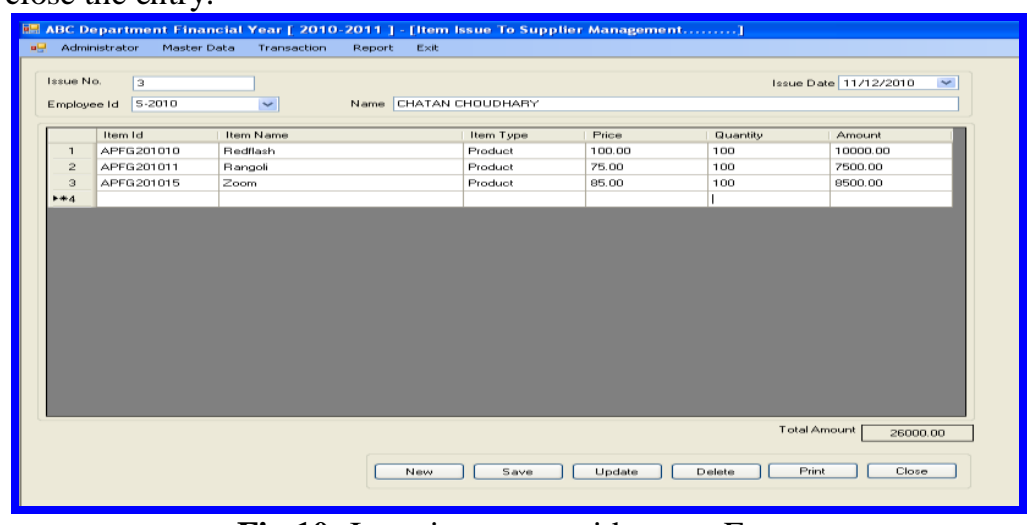

Fig.10: Issue item to outside party Entry

1. Report: Report generation is used to drive the statistics of the issues inventory database Based on the required parameters. Transaction reports list details for issue and receive transactions items in a specific date account over a specified period, Stock Statement for particular items. Report generation classified three types:

A. Stock Statement

B. Issue Register

C. Receive Register

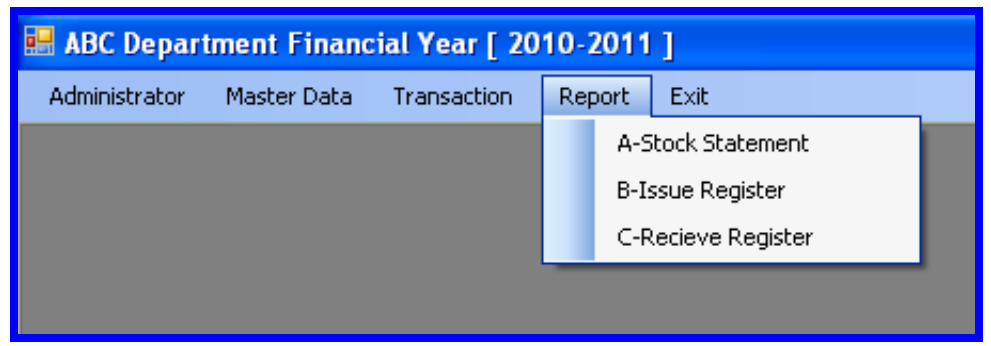

Fig.11 Type of Report

A- Stock statement: Stock of item statement report generates according to the item id or item type. 


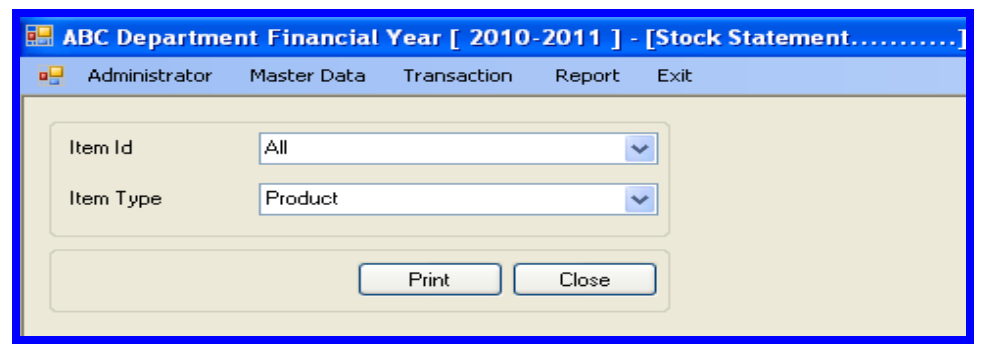

Fig.12: stock Statement

B- Issue Register: Issue of item according to the party wise between two specific dates.

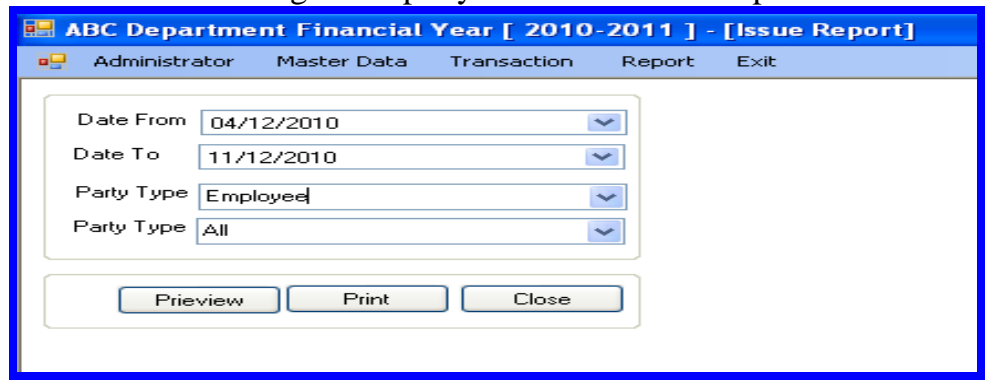

Figure-12: Issue Register

C-Receive Register: Receive of item report generate according to the party wise between two specific dates.

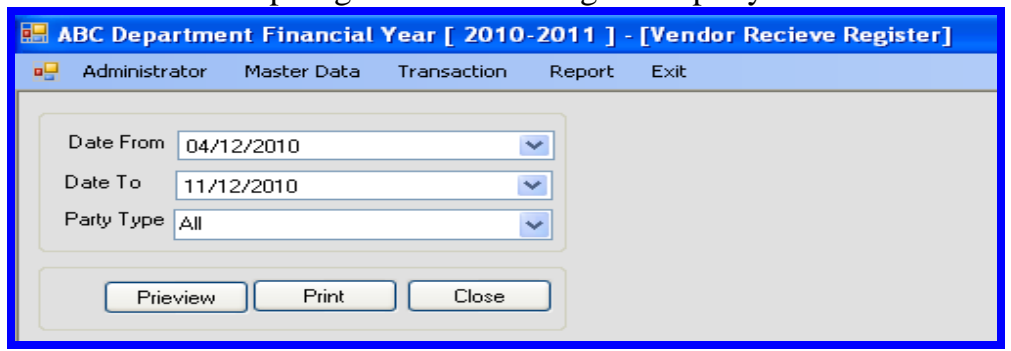

Fig.13: Receive Register

\section{Conclusion}

In the present works the various steps involved in the Software Engineering process like feasibility study, Requirement analysis, System Designing \& Documentation, coding \& implementation, System Testing, delivering, maintenance were implemented in developing software package for inventory management. It provides the easy, fast, accurate and efficient system for the user. In this system the record of the each request details are preserved along with their transaction related to them. The system is also made secured as all the updating and transaction can be done by the authorized person. The main purpose of present work is to give all details about the Items transaction in the Inventory such as, Item issuing, Items receiving, \& Report generation about the stock statement, Issue Register, \& receive register were successfully developed.

\section{Future Scope}

- The cloud-based ERP systems are now taking over the traditional methods of managing data and processes because of its various advantages such as provide enhanced data storage capacity, security and control, give a real-time access from anywhere, reduced hardware $\&$ server cost etc.

- Mobiles-based ERP system - It will have various advantages compare to traditional ERP System such as faster decision making, Greater operational efficiencies, Improved communication and collaboration, anytime access to enterprise, business and manufacturing intelligence, improved workflow and expedited approval process, improved responsiveness to customer and prospect needs and inquiries etc.

\section{References}

[1]. Alexis L., ERP Demystified (Tata McGraw- Hill Publishing Company Ltd., New Delhi,2000)

[2]. Al-Mashari, M. \& Al-Mudimigh, A. (2006): ERP implementation lessons from a case study, Journal of Information technology, 16(1), 2006, 21-23.

[3]. APICS , American Production and Inventory Control Society (APICS), http://www.apics.org., 2001

[4]. Bayross, I., SQL, PL/SQL the programming language of Oracle (BPB publication, New Delhi, 2009)

[5]. Bhatia M. S., A Beginner's Guide to Visual basic 6 (Khanna book publishing company (P) Ltd., Delhi, 2007.) 
[6]. Chumney, M.W., Wyeth, M. \& Sullivan, J.J., Developing a Practical Framework for ERP Project Implementation: A Proposed Research Design, Journal of International Federation for Information Systems, 9 (1), 2006, 341-351.

[7]. Ehie, L.C., \& Madsen, M., Identifying Critical Issues in ERP Implementation, International Journal of applied engineering research, Vol. 56, 2005, 545-557.

[8]. Gargeya, V.B. \& Brady, C. (2005): Success and failure factor of adopting SAP in ERP system Implementation, Business Process Management journal, 11(9), 2005, 175-197.

[9]. Huang,Z. \& Palvia, P. , Implementation issues in advanced and developing Countries, Business Process Management Journal, 7(3), 2001, 285-296.

[10]. Kalbasi, H. (2007): Assessing ERP Implementation Critical success factors, Master Thesis, Tarbiat Modares University, 2007

[11]. Kumar, K. and Van Hillsgersberg, J., ERP experiences and evolution. Communications of the ACM, 43(4), $2000,23-26$.

[12]. Law, H.C. \& Nagi, T.W., ERP Systems Adoption and Exploratory Study Of The organizational Factors and Impacts of ERP Success, Journal of Information And Management, Vol. 44, 2007, 418-432.

[13]. Lawton, G., Integrating ERP and CRM via the Web (SW Expert-2000)

[14]. O. Leary, D. E., Enterprise Resource Planning Systems: Systems, Life Cycle, Electronic Commerce, and Risk. UK (Cambridge University Press 2000)

[15]. Rahul V. Altekar, Enterprise Resources Planning (PHI Private Ltd. New Delhi- 2005)

[16]. Stratman, J.K. \& Roth, A.V., Enterprise resource planning (ERP) competence construct: two-stage multi-item scale development and validation, Decision Science, 33(4), 2008, 601-628.

[17]. Tadjer, R. , Enterprise resource planning (Internet week, Manhasset, 1998 April 13)

[18]. Wallace, T.F., \& Kremzar, M.J., Enterprise resource planning \& application integration, Business process Management Journal, 7(3), 2001, 195-204.

[19]. Walther S., ASP.NET 3.5 (SAMS Publication Delhi 2009)

[20]. Yadav, P.K., Database management system (Publication S.K. Kataria \& Sons 2009)

[21]. Choudhary, S. K., Suman, R., Gupta, N., Designing the Process of Stores Management for Implementing ERP in Manufacturing Organization: Case Study, Industrial Engineering Letters, International Institute of Science Technology \& Education, 4(3), 2014, 49-66.

[22]. Suman, R, Chaudhary S.K., Preet, P., Computer Govern Maintenance System for a Process Industry, Computer Engineering and Intelligent Systems, IISTE, 5,(3), 2014, 17-24. 